\title{
Using cost-effectiveness analysis to support policy change: varenicline and nicotine replacement therapy for smoking cessation in Jordan
}

Saba Madae'en ${ }^{1 *}$, Nour Obeidat ${ }^{2}$ and Mohammad Adeinat ${ }^{3}$

\begin{abstract}
Background: Smoking cessation pharmacotherapies (SCPs) have been established as cost-effective for the treatment of tobacco use disorder across a variety of settings. In Jordan, a resource-constrained country where smoking rates rank at one of the highest globally, the cost-effectiveness of SCPs has not yet been quantified. The lack of information about the value of SCPs has contributed to low demand for them (from public and private payers) and consequently low availability of these medications. The aim of this study was to simulate-in a hypothetical cohort of Jordanian smokers - the clinical and economic impact of using two smoking cessation regimens and to generate cost-effectiveness values that can support policy changes to avail smoking cessation medication in a country burdened with heavy tobacco use.

Methods: We employed a similar approach to a widely used economic model, the Benefits of Smoking Cessation on Outcomes (BENESCO) model. A hypothetical cohort of Jordanian male smokers aged 30 to 70 years and making a quit attempt using either a varenicline regimen or a nicotine replacement therapy (NRT) regimen were followed over time (until reaching 70 years of age). Markov simulations were run for the cohort, and life years gained were computed for each arm (compared to no intervention). Drug costs, prevalence of smoking, and population life expectancies were based on Jordanian data. Efficacy data were obtained from the literature. Incremental cost-effectiveness ratios as well as the potential budgetary impact of employing these regimens were generated. Several parameters were modified in sensitivity analyses to capture potential challenges unique to Jordan and that could impact the results.

Results: For a treatment cohort of 527,118 Jordanian male smokers who intended to quit, 103,970 life years were gained using the varenicline regimen, while 64,030 life years were gained using the NRT regimen (compared to the no-intervention arm of life years). The cost per life year gained was JD1204 (\$1696 USD) and JD1342 (\$1890 USD) for varenicline and NRT, respectively.
\end{abstract}

Keywords: Smoking cessation, Varenicline, Cost-effectiveness, Nicotine replacement therapy, Jordan

\footnotetext{
* Correspondence: s.madain@ju.edu.jo

'Department of Biopharmaceutical and Clinical Pharmacy, University of Jordan, Amman 11941, Jordan

Full list of author information is available at the end of the article
} 


\section{Background}

The age-adjusted prevalence of smoking in Jordan ranks among the highest worldwide, having reached $70.2 \%$ in males [1]. Overall, the smoking prevalence is approximately $32 \%$, but among middle-aged males, prevalence rates reach as high as $61 \%$ [2]. The negative health consequences of smoking are irrefutable: active smoking is associated with numerous diseases and conditions, including cardiovascular and respiratory diseases, negative reproductive effects in both males and females, rheumatoid arthritis, reduced immune function, overall diminished health, and at least 15 types of cancers [3]. Globally, developing countries are particularly hard-hit as a result of scarce resources to manage smokinginduced morbidity and mortality [4, 5]. Availing smoking cessation pharmacotherapies (SCPs) to assist smokers in quitting can considerably alleviates this burden [4].

In Jordan, only $20 \%$ of smokers in Jordan reported receiving medical advice to quit smoking, while approximately $63 \%$ had tried but failed to quit [6]. Tobaccodependence treatment guidelines have since been established for the country [7], but bulk procurement of firstline, smoking cessation medications [approved by the US Food and Drug Administration (FDA) as well as the European Medicines Agency] does not take place. Thus, these medications (oral agents varenicline and bupropion, medications that alter the release or uptake of dopamine in the brain and can partially block nicotinic receptors; and nicotine replacement therapies in the forms of gum, lozenge or patch, which provide nicotine in lower concentrations than that found in cigarettes) [8] are not available in a consistent and sufficient quantity in the Jordanian public sector [7]. This is unfortunate, given the evidence that SCPs work. In one of the most recent global clinical trials comparing multiple SCPs, varenicline was associated with 6-month abstinence rates of approximately $25 \%$, while bupropion or NRTs (transdermal patches) were associated with abstinence rates of approximately 18\% [9]. Evidence also indicates that extending the use of or combining different SCPs can increase abstinence rates [8]. Practically, the availability of a selection of SCPs, rather than only one medication (for example, only varenicline), is critical to the treatment process. This is because the selection of a SCP is tailored to patient preference as well as patient response [10] and may need to be modified during treatment.

One of the reasons contributing to the lack of urgency to promote SCPs on a national level has been the limited evidence on the pharmacoeconomic value of SCPs from the Jordanian healthcare perspective. While the costeffectiveness of SCPs has been demonstrated in various Western settings [11], the results cannot be directly extrapolated to developing countries such as Jordan due to differences in prevalence of smoking, population distributions, patient characteristics, and drug pricing.

Our research aims to fill a major information gap by assessing the potential clinical and economic impact of two FDA-approved SCPs from a Jordanian public payer perspective, and accordingly quantifying the costeffectiveness values for these SCPs if used in Jordan. We were specifically interested in examining whether or not these medications-if employed in a Jordanian population and using Jordanian drug prices-would yield comparable health benefits (quantity of life years gained) as reported in literature from other countries. We also were interested in estimating the budget impact of using such medications in Jordan.

\section{Methods \\ Study design}

We conducted a cost-effectiveness analysis on a hypothetical cohort of Jordanian smokers representing the current age distribution of the Jordanian population $[12,13]$.

\section{Modeling approach and comparators}

Many models have been used to test the cost-effectiveness of SCPs [11]. We referred to the approach used by specific studies [14, 15]. Specifically, we used a Markov model which allowed for one treatment event (at year one) and would follow the cohort until 70 years of age. We thus modeled smoking cessation in a dynamic (time-varying manner) while also taking into account the risks for relapse after 52 weeks.

Three possible intervention arms were used: treatment with varenicline for 3 months, treatment with NRTs (combined patch and gum) for 3 months, and physician advice over three visits with no medications. Both varenicline and the NRT forms selected for our model are approved by the Jordanian FDA (JFDA) for purchasing and use.

Cycles of 1-year length were used. For each arm, the model included three states at the end of the first year: continuing to smoke at 52 weeks, being a quitter at 52 weeks, or being dead. Subsequent to this year, smokers could stop smoking unaided, continue to smoke, or die; quitters could remain abstinent, relapse to smoking, or die. A time horizon of 40 years or up to 70 years of age was used. A schematic of this is presented in Fig. 1, which depicts the cycle for the first year and then subsequent years for varenicline users, and the probabilities of each state transition.

\section{Perspective}

The analysis used the Jordanian Ministry of Health (public payer) perspective. 


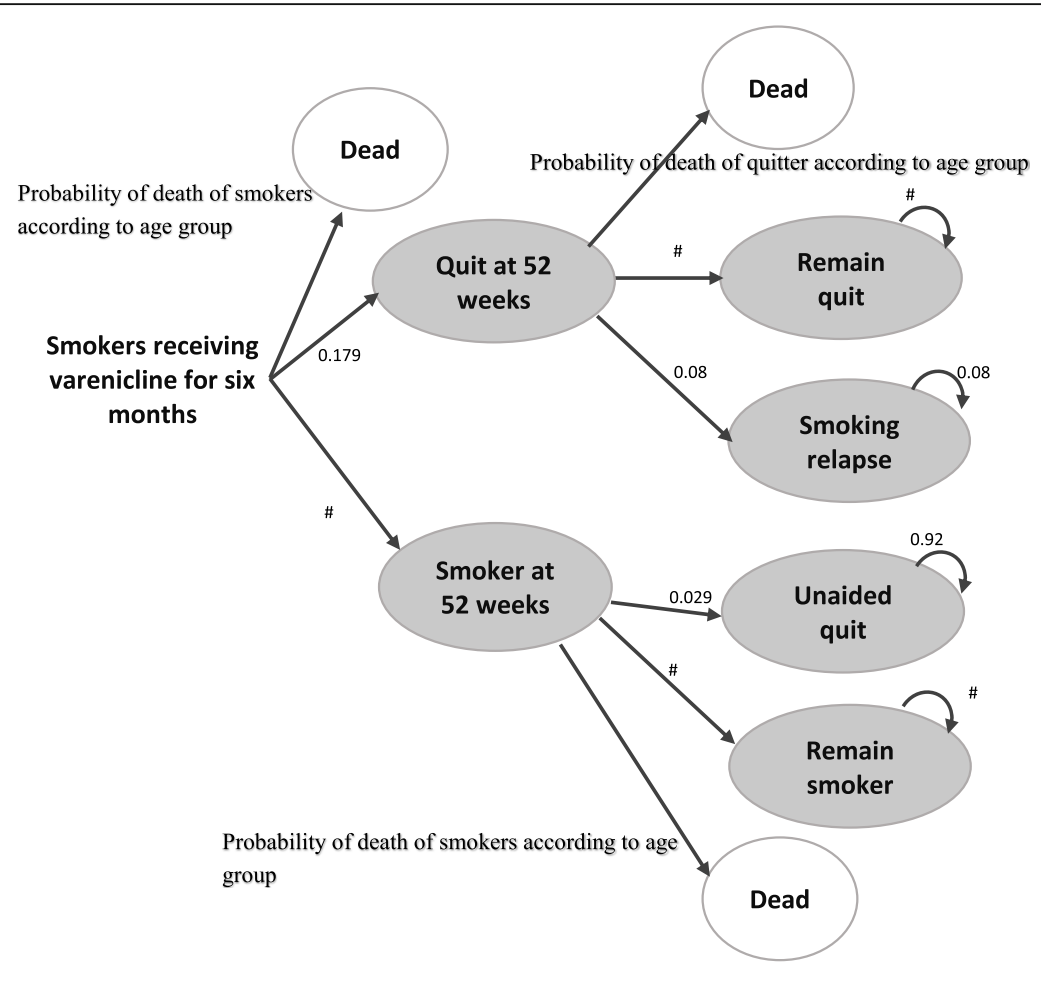

Year 1

Year 2 and subsequent years

*The (\#) represents the remaining probability

Fig. 1 Schematic of model for a single arm (e.g., varenicline users). The number sign represents the remaining probability

\section{Population}

This hypothetical study cohort was composed of male smokers in Jordan aged 30 years or older who intended to quit smoking. We chose the male population due to the substantially higher prevalence of smoking among males in the country [2]. Specifically, we constructed the final cohort using 2016 population estimates of Jordan [13]. We applied smoking prevalence rates by male agegroups [2] as well as proportions of smokers willing to quit smoking [16] to the 2016 population estimates to generate the starting population of Jordanian male smokers who would be receiving a smoking cessation intervention.

\section{Costs}

We included only medication costs and costs for physician visits. Similar to other studies $[9,17,18]$, we did not include the adverse events of smoking cessation medications due to their relative safety, and due to the fact that incidence of adverse events (such as nausea and headaches) usually do not require major medical interventions.

\section{Time horizon}

We followed each age group up to 70 years of age. Annual cycles were included in the model to reflect the annual probabilities of death.

\section{Discount rate employed}

An annual 3\% discount rate was used for all inputs and rewards. The issue of discount rate selected continues to be debated, but we selected the lower of the two most commonly used rates in the literature [19].

\section{Effectiveness of smoking cessation interventions}

We used similar 52-week abstinence rates for the smoking cessation regimens used by Baker and Pietri [20] and which were imputed from the latest randomized controlled EAGLES trial [9]. The effectiveness of brief counseling was an approximate value (5\%) taken from key reviews $[21,22]$. 


\section{Benefits of smoking cessation}

We used life years gained as the main benefit of smoking cessation. We did not have sufficient information specific to the Jordanian healthcare setting to generate morbidity or event-specific costs (such as costs associated with altered rates of tobacco-related diseases). We used Jordanian life table numbers to obtain the death rate for each age group of male Jordanians [13]. We then used Taylor et al.'s study to calculate the hazard ratio of death for smokers in each group, as well as the hazard for death in quitters according to the time since they quit [23].

\section{Outcomes}

We generated life years gained as a result of smoking cessation through medication use in each arm (varenicline and NRTs), compared to no medication use. We also generated the total direct costs incurred as a result of medication use. Finally, costs per life years gained were calculated as a measure of incremental costeffectiveness.

\section{Threshold}

More than one method has been proposed to determine cost-effectiveness thresholds [24-26]. To address the variable estimates of thresholds, we opted to interpret our results using more than one threshold. A relatively generous threshold of one to three times the gross domestic product (GDP) per capita was considered [24], as was a more conservative threshold that was approximately 0.21 to 0.84 times the GDP [25]. Jordan's per capita GDP in 2019 was estimated at JD3116 (\$4395 USD) [27]. Thus, a generous threshold of JD3116 (\$4395 USD) was considered, as was a conservative threshold of JD1636 (\$2307 USD) (the midpoint for the range suggested by Woods et al. [25] was used to calculate this). Table 1 summarizes the parameters used in the Markov model.

Analyses were performed using the TreeAge Pro software program [30].

\section{Sensitivity analyses}

We addressed the uncertainty in the base case by varying the values of specific input parameters. Specifically, sensitivity analyses were performed in which we varied medication effectiveness rates (relapse rates) and prescription treatment costs. Parameter uncertainty (variability) was reflected either using 95\% confidence intervals or the differences in estimates across studies.

Table 1 Overview of parameters used in the base case analysis of cost-effectiveness of varenicline, combined nicotine replacement therapy, or no pharmacotherapy

\begin{tabular}{|c|c|c|}
\hline Parameter & Value & Reference (if applicable) \\
\hline Prevalence of smokers per age group & $30-39,61.3 \% ; 40-49,61.4 \% ; 50-59,62.3 \% ; 60+, 24.8 \%$ & Jaghbir et al. [6] \\
\hline $\begin{array}{l}\text { Prevalence of smokers intending to quit in the next } 30 \\
\text { days }\end{array}$ & $49 \%$ & Abughosh et al. [16] \\
\hline \multicolumn{2}{|l|}{ Effectiveness (derived 52-week abstinence rates) } & \multirow{4}{*}{$\begin{array}{l}\text { Baker and Pietri, Fiore et al., Stead } \\
\text { et al. [20-22] }\end{array}$} \\
\hline Varenicline & $17.9 \%$ & \\
\hline NRTS & $13.3 \%$ & \\
\hline No medication (single physician visit) & $5.0 \%$ & \\
\hline $\begin{array}{l}\text { Probability of remaining abstinent having quit by } 52 \\
\text { weeks }\end{array}$ & $95 \%$ & Hughes et al. [28] \\
\hline Risk of relapse after one year of abstinence & $8 \%$ & Hughes et al. [28] \\
\hline Unaided quit in subsequent years & $2.9 \%$ & Jaghbir et al. [6] \\
\hline $\begin{array}{l}\text { Jordanian life table numbers were used to obtain the } \\
\text { gender-specific death rate for each age group. We } \\
\text { then used Taylor et al.'s study to derive the hazard ra- } \\
\text { tio of death for smokers in each group, plus the hazard } \\
\text { for death among quitters according to the time since } \\
\text { they quit (Appendix 1) }\end{array}$ & $\begin{array}{l}30-34 \text { years, } 0.005 \times 1.6875 ; 35-39 \text { years, } 0.007 \times \\
1.6875 ; 40-44 \text { years, } 0.011 \times 2.34 ; 45-49 \text { years, } 0.018 \times \\
2.34 ; 50-54 \text { years, } 0.03 \times 2.82 ; 55-59 \text { years, } 0.051 \times \\
2.82 ; 60-64 \text { years, } 0.081 \times 2.80 ; 65-69 \text { years, } 0.129 \times \\
2.80 ; 70-74 \text { years, } 0.205 \times 2.52\end{array}$ & WHO and Taylor et al. [1, 23] \\
\hline \multicolumn{2}{|l|}{ Costs of treatment (US dollars) } & \multirow{4}{*}{$\begin{array}{l}\text { Pharmaceutical unit prices retrieved } \\
\text { from the Jordanian Food and Drug } \\
\text { Administration (JFDA) [29] }\end{array}$} \\
\hline Varenicline, physician visits (3 months) & 270.00 & \\
\hline NRTs, physician visits (3 months) & 192.00 & \\
\hline No medication (three physician visits) & 21.00 & \\
\hline Discount rate & $3 \%$ & Attema et al. [19] \\
\hline Cost-effectiveness threshold & $\begin{array}{l}\text { JD3116/\$4395 (generous); JD1636/\$2307 } \\
\text { (conservative)*; JD8000 by WHO }\end{array}$ & $\begin{array}{l}\text { Woods et al. and } \\
\text { WHO }[24,25]\end{array}$ \\
\hline
\end{tabular}

*The midpoint was selected for a range (approximately 0.21 to 0.84 times the per capita GDP) calculated by Woods et al. 
The tested parameter intervals are shown in Table 3. Each input was considered in isolation in a deterministic one-way sensitivity analysis for each arm.

In a probabilistic sensitivity analysis, we considered all input uncertainties simultaneously, using Monte Carlo simulation $(10,000$ simulations in different combinations) to yield a single $95 \%$ confidence interval of simulations for varenicline cost per life year saved in comparison to brief counseling.

\section{Results}

\section{Cost-effectiveness}

For a treatment cohort of 527,118 Jordanian male smokers who intended to quit, 103,970 life years were gained using the varenicline regimen, while 64,030 life years were gained using the NRT regimen (compared to the no-intervention arm). The cost per life year gained was JD1204 (\$1696 USD) and JD1342 (\$1890 USD) for varenicline and NRT, respectively. Results of the base case scenario are presented in Table 2. Overall life years gained from varenicline use was 0.197 life years per smoker intending to quit (being highest at age 30, with 0.26 life years gained) and 0.121 life years gained from nicotine replacement therapy.

\section{Population and budget impact}

In terms of population impact if, hypothetically, all Jordanians intending to quit smoking in the next month sought a practitioner and were managed with a 3-month course of varenicline or NRTs (rather than brief counseling sessions), 94,970 and 64,030 additional life years would be gained using varenicline or NRTs, respectively. These would cost the MoH (Ministry of Health) $(\$ 135,748,710$ USD) $96,381,584 \mathrm{JD}$ and $(\$ 96,532,416 \mathrm{USD}) 68,538,015 \mathrm{JD}$ (respectively).

\section{Sensitivity analysis results}

The results of the sensitivity analysis are displayed in Table 3.

The input that had the widest range for cost per life year for varenicline was the effectiveness of varenicline. At an effectiveness rate of $15 \%$ for example, the cost per life year saved for varenicline was JD7500 (\$10,563 USD) in relation to NRT. When costs were varied due to the anticipation that-in reality-bulk purchasing can result in lower unit costs paid by the Jordanian $\mathrm{MoH}$ and that generic formulations may become available, the lowest prices of varenicline or high price of NRTs yielded negative, showing that varenicline dominates.

Probabilistic sensitivity analysis yielded, in simulations for varenicline in comparison to brief counseling, a range for cost per life year saved of (397-7500) JDs.

\section{Discussion}

The aim of our analysis was to compare the population benefits (in terms of life years gained) of using smoking cessation medications in a hypothetical cohort of Jordanian smokers. Our analysis yielded 0.26 and 0.12 additional life years gained per smoker using varenicline or nicotine replacement therapy to quit (relative to brief advise from a healthcare practitioner). These values are comparable to the ranges reported in the literature [14, 20,31]. The incremental costs per life year gained were JD1204 (\$1696 USD) and JD1342 (\$1890 USD) for varenicline and NRTs, respectively. Using either cost-effectiveness threshold, we concluded that provision of varenicline is a cost-effective intervention, while provision of NRTs is likely to also be cost-effective (given our thresholds were based on a range).

Our cost-effectiveness estimates for both smoking cessation medication regimens are the first to be generated for Jordan, a country in which smoking prevalence now ranks as one of the highest worldwide [1]. Our results are important and confirm that even in a low-resource country such as Jordan, smoking cessation medications are a cost-effective intervention to avail. Furthermore, our results are conservative. We anticipate, if these medications are to become among the list of medications purchased by the Ministry of Health, that these regimens will in reality be far more cost-effective. Our drug prices in the analysis were based on values listed in Jordan's FDA, which lists wholesale and pharmacy prices for medications when they are first registered [29]. In reality, due to the government's bulk purchasing of medications through Jordan's Joint Procurement Department (JPD), unit costs of medications are substantially lower than the listed wholesale and pharmacy prices: for example, in 2016, the JPD reported purchasing medications at approximately $40 \%$ of their market price [32]. Furthermore, given the fact that Jordan's JPD is likely to acquire smoking cessation medications at much lower prices than those initially listed (market price), the budget impact of using smoking cessation medications is also going to be much lower than our estimated impact of JD135,748,710 (\$96,381,584 USD) (for varenicline) and JD96,532,416 (\$68,538,015 USD) (for NRTs). Finally, with regard to this matter in particular, the potential for generic bupropion, cytisine, and (in the future) generic varenicline to be availed further supports the feasibility of providing smoking cessation medications on a national level.

Treating tobacco dependence is a particularly critical clinical service for Jordan, given the burden of smoking the country faces. Such an intervention is important for primary, secondary, and tertiary disease prevention and control. In fact, treating tobacco dependence is more effective than other preventive services that tend to be 
Table 2 Life years gained and medication costs incurred per treatment arm and age group

\begin{tabular}{|c|c|c|c|c|}
\hline & Cost (in JDs) & Life years & Number intending to quit & Cycles \\
\hline \multicolumn{5}{|l|}{ Age 30-34 } \\
\hline Varenicline & $33,043,140$ & $2,829,590$ & 123,476 & 40 \\
\hline NRT & $23,497,344$ & $2,815,827$ & 123,476 & 40 \\
\hline Brief counseling & $2,570,022$ & $2,797,447$ & 123,476 & 40 \\
\hline \multicolumn{5}{|l|}{ Age 35-39 } \\
\hline Varenicline & $29,199,690$ & $2,013,904$ & 109,453 & 35 \\
\hline NRT & $20,764,224$ & $2,004,786$ & 109,453 & 35 \\
\hline Brief counseling & $2,271,087$ & $1,986,592$ & 109,453 & 35 \\
\hline \multicolumn{5}{|l|}{ Age $40-44$} \\
\hline Varenicline & 24997680 & 1330153 & 95,062 & 30 \\
\hline NRT & 17776128 & 1321244 & 95,062 & 30 \\
\hline Brief counseling & 1944264 & 1306761 & 95,062 & 30 \\
\hline \multicolumn{5}{|l|}{ Age $45-49$} \\
\hline Varenicline & $20,887,200$ & 825,156 & 80,768 & 25 \\
\hline NRT & $14,853,120$ & 820,792 & 80,768 & 25 \\
\hline Brief counseling & $1,624,560$ & 812,682 & 80,768 & 25 \\
\hline \multicolumn{5}{|l|}{ Age 50-54 } \\
\hline Varenicline & 14668560 & 408252 & 59,340 & 20 \\
\hline NRT & 10430976 & 405324 & 59,340 & 20 \\
\hline Brief counseling & 1140888 & 402227 & 59,340 & 20 \\
\hline \multicolumn{5}{|l|}{ Age 55-59 } \\
\hline Varenicline & $9,338,760$ & 182,218 & 40,366 & 15 \\
\hline NRT & $6,640,896$ & 181,688 & 40,366 & 15 \\
\hline Brief counseling & 726,348 & 180,711 & 40,366 & 15 \\
\hline \multicolumn{5}{|l|}{ Age $60-64$} \\
\hline Varenicline & $2,271,510$ & 32,060 & 10,883 & 10 \\
\hline NRT & $1,615,296$ & 31,897 & 10,883 & 10 \\
\hline Brief counseling & 176,613 & 31,363 & 10,883 & 10 \\
\hline \multicolumn{5}{|l|}{ Age $65-70$} \\
\hline Varenicline & $1,342,170$ & 13,045 & 7770 & 5 \\
\hline NRT & 954,432 & 12,880 & 7770 & 5 \\
\hline Brief counseling & 104,391 & 12,625 & 7770 & 5 \\
\hline \multicolumn{5}{|c|}{ Total } \\
\hline Varenicline & $135,748,710$ & $7,625,378$ & 527,118 & 180 \\
\hline NRT & $96,532,416$ & $7,594,438$ & 527,118 & 180 \\
\hline Brief counseling & $10,558,173$ & $7,530,408$ & 527,118 & 180 \\
\hline
\end{tabular}

more widely promoted [28]. For example, the number needed to treat to avoid one death (NNTs) in the case of a basic smoking cessation service with $6 \%$ effectiveness is 67 , and the NNT for a more intensive service with $12 \%$ effectiveness is 22 . These numbers compare very favorably to the NNTs of preventive services such as lifetime treatment with daily aspirin (NNT 40 to prevent an early death from heart disease), statins use (NNT 71), or mammograms to prevent cancer deaths in women aged 50 to 59 (number needed to screen, 351) [28, 33, 34].

Our study limitations largely stem from the lack of clinical and disease-specific economic data applicable to Jordan. We adopted a simplistic approach in our modeling and did not account for changing transition probabilities for events such as changing interest in quitting. We did not account for clinical outcomes preceding 
Table 3 Results of deterministic one-way sensitivity analyses for the cost of life year saved by varenicline compared to nicotine replacement therapy

\begin{tabular}{llll}
\hline Variable & Base case value & Range varied & Cost per life year gained in JDs (ICER) \\
\hline Effectiveness of varenicline & 0.179 & $0.15-0.215$ & $1050-7500$ \\
Effectiveness of nicotine replacement therapy & 0.133 & $0.1-0.15$ & $400-1100$ \\
Effectiveness of brief counseling & 0.076 & $0.029-0.077$ & $500-2500$ \\
Cost of varenicline $(\$)$ & 270 & $140-400 \mathrm{JD}$ & Dominant \\
Cost of NRT (\$) & 192 & $90-380 \mathrm{JD}$ & Dominated \\
\hline
\end{tabular}

death, such as incidence and costs of tobacco-related diseases, and did not include indirect costs of smoking such as lost productivity due to morbidity or mortality. We also assumed that the effectiveness of smoking cessation medications in the literature is generalizable to the Jordanian population. Furthermore, we did not simulate our cohort further than 70 years of age, because we did not have data beyond this age group. Finally, due to the on-going debate about what cost-effectiveness thresholds should be used in evaluating interventions, it is difficult to decisively make statements about the costeffectiveness of either varenicline or NRTs, although we draw scenarios in our sensitivity analysis that strongly suggest that, in reality (with changing unit costs due to the government's procurement process), the use of these regimens will be very cost-effective.

Despite these limitations, our study is the first to our knowledge to showcase one aspect of the value of smoking cessation medication (life years gained). Our findings can be used in strengthening the dialog about the value of smoking cessation medications in clinical practice.

\section{Supplementary information}

Supplementary information accompanies this paper at https://doi.org/10. 1186/s40545-020-00270-y.

Additional file 1: Appendix 1. Jordanian ex-smokers' probability of death*

\section{Abbreviations}

SCPs: Smoking cessation pharmacotherapies; NRT: Nicotine replacement therapy; BENESCO: The Benefits of Smoking Cessation on Outcomes; FDA: Food and Drug Administration; GDP: Gross domestic product; JPD: Joint Procurement Department; MoH: Ministry of Health; NNT: Number needed to treat to avoid one death; WHO: World Health Organization

\section{Acknowledgements}

None

\section{Authors' contributions}

We attest to the fact that all the authors listed on the title page have contributed significantly to the work, have read the manuscript, and attest to the validity and legitimacy of the data and its interpretation. The authors read and approved the final manuscript.

\section{Funding}

The authors received no specific funding for this work.

\section{Availability of data and materials}

All data generated or analyzed during this study are included in this published article [and its supplementary information files].

\section{Competing interests}

The authors declare that they have no competing interests.

\section{Author details}

${ }^{1}$ Department of Biopharmaceutical and Clinical Pharmacy, University of Jordan, Amman 11941, Jordan. ${ }^{2}$ King Hussein Cancer Centre, Amman, Jordan. ${ }^{3}$ Department of Economics, University of Jordan, Amman, Jordan.

Received: 15 February 2020 Accepted: 4 September 2020

Published online: 27 October 2020

\section{References}

1. WHO. World Health Organization. Prevalence of tobacco smoking. Agestandardized prevalence of current tobacco smoking among persons aged 15 years and older (\%), 2015: Male. Retreived from http://gamapserver.who. int/gho/interactive_charts/tobacco/use/atlas.html. 2015.

2. Jaghbir M, Shreif S, Ahram M. Pattern of cigarette and waterpipe smoking in the adult population of Jordan. Eastern Mediterranean health journal $=\mathrm{La}$ revue de sante de la Mediterranee orientale = al-Majallah al-sihhiyah lisharq al-mutawassit. 2014;20(9):529-37.

3. National Center for Chronic Disease P, Health Promotion Office on S, Health. Reports of the surgeon general. The health consequences of smoking-50 years of progress: a report of the surgeon general. Atlanta (GA): Centers for Disease Control and Prevention (US); 2014.

4. Ekpu VU, Brown AK. The economic impact of smoking and of reducing smoking prevalence: review of evidence. Tobacco Use Insights. 2015;8:1-35.

5. Goodchild M, Nargis N, Tursan d'Espaignet E. Global economic cost of smoking-attributable diseases. Tob Control. 2018;27(1):58-64.

6. Jaghbir M, Shareif S, Ahram M. Quitting smoking and utilization of smoking cessation services in Jordan: a population-based survey. Eastern Mediterranean health journal = La revue de sante de la Mediterranee orientale = al-Majallah al-sihhiyah li-sharq al-mutawassit. 2014;20(9):538-46.

7. Ayub H, Obeidat N, Leischow S, Glynn T, Hawari F. Jordan tobacco dependence treatment guidelines: rationale and development. Eastern Mediterranean health journal $=$ La revue de sante de la Mediterranee orientale = al-Majallah al-sihhiyah li-sharq al-mutawassit. 2016;21(11):844-50.

8. U.S. Department of Health and Human Services. Smoking cessation. A report of the surgeon general, U.S. Department of Health and Human Services, Centers for Disease Control and Prevention, National Center for Chronic Disease Prevention and Health Promotion, office on smoking and health, 2020. Atlanta, GA; 2020.

9. Anthenelli RM, Benowitz NL, West R, St Aubin L, McRae T, Lawrence D, et al. Neuropsychiatric safety and efficacy of varenicline, bupropion, and nicotine patch in smokers with and without psychiatric disorders (EAGLES): a double-blind, randomised, placebo-controlled clinical trial. Lancet (London, England). 2016;387(10037):2507-20.

10. Barua RS, Rigotti NA, Benowitz NL, Cummings KM, Jazayeri MA, Morris PB, et al. 2018 ACC expert consensus decision pathway on tobacco cessation treatment: a report of the American College of Cardiology Task Force on clinical expert consensus documents. J Am Coll Cardiol. 2018;72(25):3332-65.

11. Berg ML, Cheung KL, Hiligsmann M, Evers S, de Kinderen RJA, Kulchaitanaroaj $P$, et al. Model-based economic evaluations in smoking cessation and their transferability to new contexts: a systematic review. Addiction. 2017;112(6):946-67. 
12. DOS. Department of Statistics. Jordan In figures 2018. http://dosweb.dos. gov.jo/products/jordan-in-figure2018/. 2018.

13. DOS. Department of Statistics. Jordan statistical yearbook. http://dosweb. dos.gov.jo/DataBank/yearbook/YearBook2016 eng.pdf. 2016.

14. Hagen G, Wisloff T, Klemp M. NIPH systematic reviews. In: Costeffectiveness of varenicline, bupropion and nicotine replacement therapy for smoking cessation. Oslo, Norway: Knowledge Centre for the Health Services at The Norwegian Institute of Public Health (NIPH) Copyright (c)2010 by The Norwegian Institute of Public Health (NIPH); 2010.

15. Howard P, Knight C, Boler A, Baker C. Cost-utility analysis of varenicline versus existing smoking cessation strategies using the BENESCO simulation model: application to a population of US adult smokers. PharmacoEconomics. 2008;26(6):497-511.

16. Abughosh $\mathrm{S}, \mathrm{Wu} \mathrm{IH}$, Hawari F, Peters RJ, Yang M. Predictors of intention to quit cigarette smoking among Jordanian adults. Epidemiol. 2011;1:103.

17. Cahill K, Lindson-Hawley N, Thomas KH, Fanshawe TR, Lancaster T. Nicotine receptor partial agonists for smoking cessation. The Cochrane database of systematic reviews. 2016 (5):Cd006103.

18. Hartmann-Boyce J, Chepkin SC, Ye W, Bullen C, Lancaster T. Nicotine replacement therapy versus control for smoking cessation. Cochrane Database Syst Rev. 2018;5:Cd000146.

19. Attema AE, Brouwer WBF, Claxton K. Discounting in economic evaluations, PharmacoEconomics. 2018;36(7):745-58.

20. Baker $C L$, Pietri $G$. A cost-effectiveness analysis of varenicline for smoking cessation using data from the EAGLES trial. Clinicoecon Outcomes Res. 2018:10:67-74

21. Fiore MC, Jaén CR, Baker TB, Bailey WC, Benowitz NL, Curry SJ, et al. Treating tobacco use and dependence: 2008 update. Clinical practice guideline. Rockville, MD: U.S. Department of Health and Human Services. Public Health Service; 2008.

22. Stead LF, Buitrago D, Preciado N, Sanchez G, Hartmann-Boyce J, Lancaster T. Physician advice for smoking cessation. The Cochrane database of systematic reviews. 2013(5):Cd000165.

23. Taylor D, Henley V, Thun M, Sloan F. Benefits of smoking cessation for longevity. Am J Public Health. 2002;92(6):990-6.

24. WHO. World Health Organization Commission on Macroeconomics and Health: macroeconomics and health: investing in health for economic development. Report of the Commission on Macroeconomics and Health. Geneva, World Health Organization 2001. Retrieved from http://www1. worldbank.org/publicsector/pe/PEAMMarch2005/CMHReport.pdf. 2001.

25. Woods B, Revill P, Sculpher M, Claxton K. Country-level cost-effectiveness thresholds: initial estimates and the need for further research. Value Health. 2016;19(8):929-35.

26. Robinson LA, Hammitt JK, Chang AY, Resch S. Understanding and improving the one and three times GDP per capita cost-effectiveness thresholds. Health Policy Plan. 2017;32(1):141-5.

27. IMF. International Monetary Fund. World Economic and Financial Surveys, World Economic Outlook database: Jordan. Retrieved from https://www.imf. org/external/pubs/ft/weo/2019/01/weodata/index.aspx. 2019.

28. Hughes JR, Peters EN, Naud S. Relapse to smoking after 1 year of abstinence: a meta-analysis. Addict Behav. 2008;33(12):1516-20.

29. JFDA. Jordanian Food \& Drug Administration. Drug pricing. Retrieved from http://www.jfda.jo/Pages/viewpage.aspx?pagelD=184. 2019.

30. TreeAge. TreeAge Pro 2018, R??? TreeAge Software, Williamstown, MA software available at http://www.treeage.com. 2018.

31. Keating GM, Lyseng-Williamson KA. Varenicline: a pharmacoeconomic review of its use as an aid to smoking cessation. PharmacoEconomics. 2010; 28(3):231-54.

32. JPD. Joint Procurement Department, Jordan. Annual Report, 2017. Retrieved from http://jpd.gov.jo/echobusv3.0/SystemAssets/7fc4af63-d6ee-469c-a46 0-155962e84286.pdf. 2016.

33. Hendrick RE, Helvie MA. Mammography screening: a new estimate of number needed to screen to prevent one breast cancer death. AJR Am J Roentgenol. 2012;198(3):723-8.

34. OCP VS, Williams S, Barchilon V, Baxter N, Jawad M, Katsaounou PA, et al. Treating tobacco dependence: guidance for primary care on life-saving interventions. Position statement of the IPCRG. NPJ Prim Care Respir Med. 2017;27(1):38.

\section{Publisher's Note}

Springer Nature remains neutral with regard to jurisdictional claims in published maps and institutional affiliations.
Ready to submit your research? Choose BMC and benefit from:

- fast, convenient online submission

- thorough peer review by experienced researchers in your field

- rapid publication on acceptance

- support for research data, including large and complex data types

- gold Open Access which fosters wider collaboration and increased citations

- maximum visibility for your research: over $100 \mathrm{M}$ website views per year

At BMC, research is always in progress.

Learn more biomedcentral.com/submissions 